\title{
Speed control of run-of-river variable speed hydro plants
}

\author{
J. Fraile-Ardanuy ${ }^{1}$, J. R. Wilhelmi, J. Fraile-Mora, J. I. Pérez and I. Sarasúa \\ ${ }^{1}$ Departamento de Ingeniería Civil: Hidráulica y Energética \\ E.T.S.I.C.C. y P., Universidad Politécnica de Madrid \\ Profesor Aranguren s/n, 28040 Madrid (España) \\ Tel.:+34 9133653 54, fax: +34 9133667 64, e-mail: jefar@caminos.upm.es
}

\begin{abstract}
The advantages of adjustable speed hydroelectric generation have been highlighted by several authors. The optimum speed for actual working conditions must be continuously implemented by means of an appropriate control system. This process gives rise to dynamic changes in operation variables. In this paper a speed control of run-of-river adjustable speed hydro plant is presented.
\end{abstract}

Key words: Adjustable speed hydro plants, dynamic response of hydro plants, induction generator, hydro plant control.

\section{Introduction}

In last years, oil prices have risen due to the need to satisfy an unprecedented growth in demand, particularly that of developing economies. Specifically, the demand of primary energy in Spain has doubled in the last 25 years [1]. The future landscape of European energy supply and demand will have to make much greater use of new renewable energy sources and focus more upon energy-efficient methods.

Using renewable energy is a central aim in the world, because it helps to reduce $\mathrm{CO}_{2}$ emissions, it enhances sustainability and it also improves the security of energy supply by reducing the growing dependence on imported energy sources.

Hydro power is the largest form of renewable energy, contributing to $23 \%$ of EU energy demand in 1998 [2]. In particular, there is a great development nowadays in the so-called Small Hydro Plants [3].

Usually hydro turbines are optimized for an operating point defined by speed, head and discharge. At fixed speed operation, any head or discharge deviation involves an important decrease in efficiency [4].
The application of variable speed generation in hydroelectric power plants offers a series of advantages, based essentially on the greater flexibility of the turbine operation in situations where the flow or the head deviate substantially from their nominal values $[2,4,5,6]$.

In small hydro plants, induction generators with shortcircuited rotor, such as squirrel cage ones, are frequently used due to its lower price, robustness and the ability to combine high efficiency and low specific cost. To allow variable-speed operation, the stator should be connected to the fixed-frequency grid through a regenerative fourquadrant frequency converter. Obviously, in these cases the rated power of the converter needs to match total generator power.

The system considered in this paper consists of a small hydro plant equipped with a variable speed induction generator connected to the fixed-frequency grid through a regenerative converter. The unit speed must be adjusted continuously to its optimum value, following changes in operational conditions.

In this paper the model of a control scheme for a run-ofthe-river variable speed small hydro plant is presented. The optimum speed reference is continuously adapted to changing operational conditions. The plant dynamic response to changes in head or discharge is described.

\section{Hydraulic system modelling}

The plant considered is a run-of-river scheme, the flow being controlled by changing the guide vanes opening to maintain the fore bay elevation in its reference value. The dynamics of this process is included in the model.

The turbine model is based on the static characteristic curves and penstock dynamics is introduced using rigid water column approximation. In Fig. 1 the Simulink ${ }^{\circledR}$ block diagram is shown. 


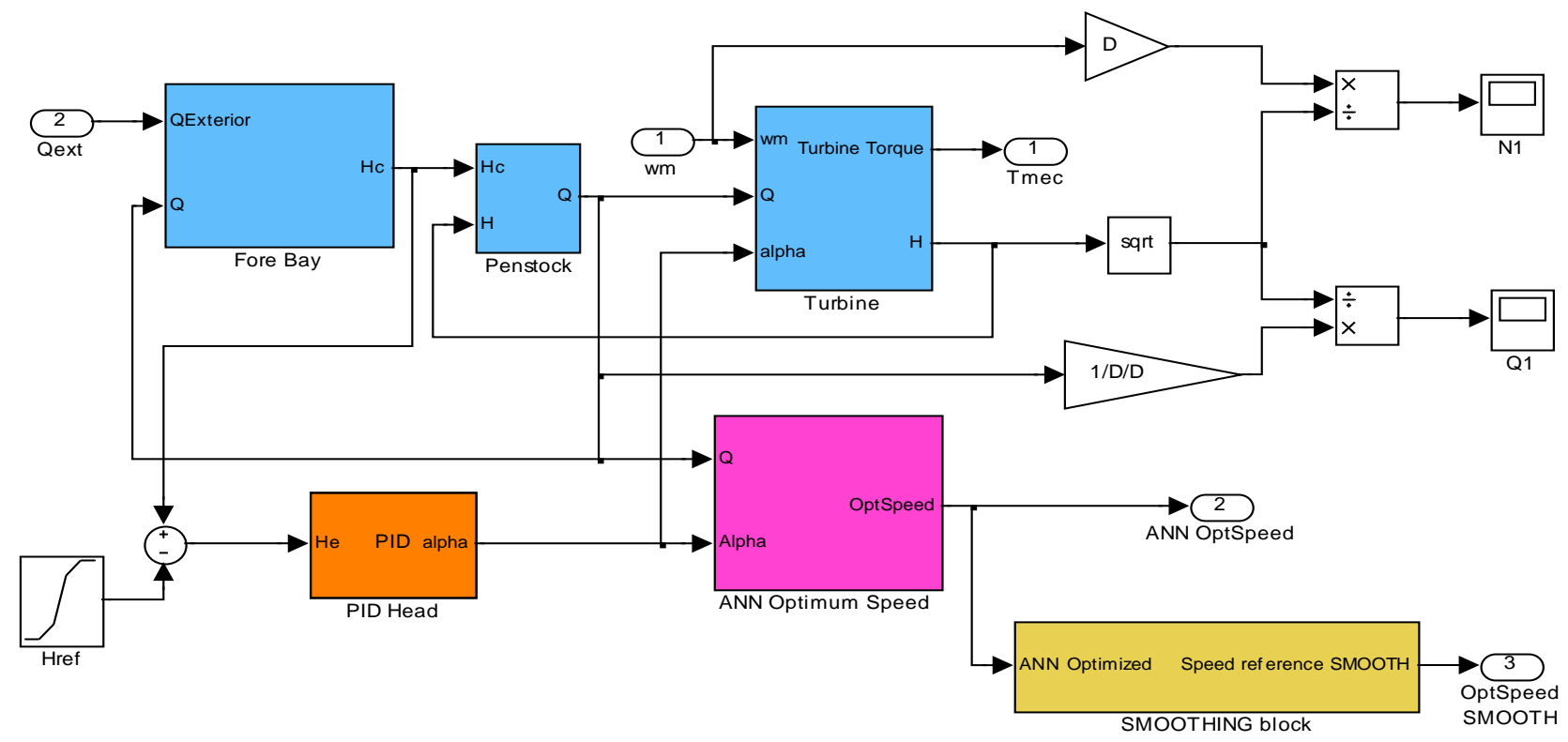

Fig. 1. Hydraulic system

The turbine performance is represented by the so-called Hill chart, shown in Fig. 2. These curves are referred to unit speed and flow, given, respectively, by following equations:

$$
n_{I}=\frac{n D_{1}}{\sqrt{H}} \quad Q_{I}=\frac{Q}{D_{1}^{2} \sqrt{H}}
$$

(See Appendix for the notation).

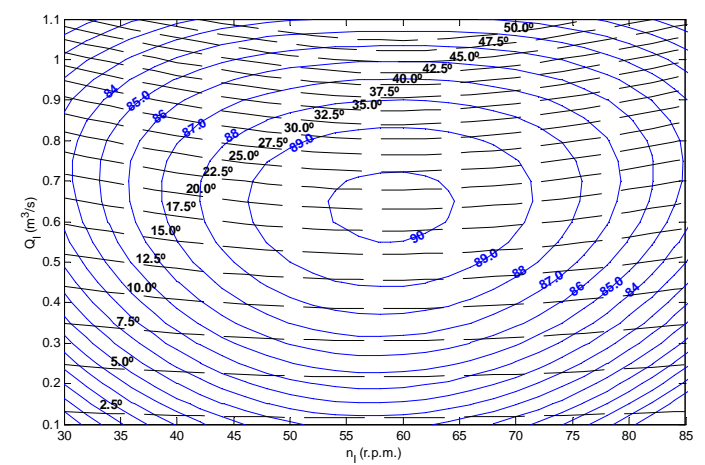

Fig. 2. Turbine hill curves

Flow dependent head losses are also included in this subsystem.

\section{ANN Optimum speed module}

Turbine reference speed must be continuously adapted to the actual operating conditions. This task is done by a module that generates the turbine speed value for which the efficiency would reach a maximum. Input variables to that module are: gate angle, or guide vanes opening, alpha and the discharge through the turbine, or turbine flow, $Q$.
As in references [7-9], an Artificial Neural Network is used to learn the behaviour of a MATLAB function designed for interpolating the best speed from the turbine hill curves. This process was found to be computationally ineffective due to the inclusion of several FOR-END loops. Therefore, the problem has been overcome by the use of the ANN. Fig. 3 depicts the optimum turbine speed in terms of gate angle and turbine flow.

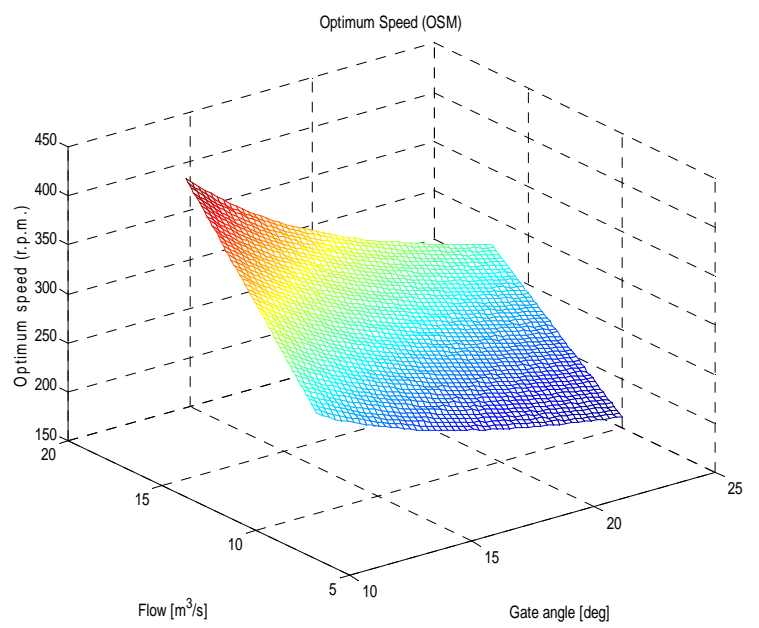

Fig. 3. OSM Surface.

In this application, the ANN used is a multilayer perceptron [8]. It has 2 neurons in the input layer (processing flow and turbine gate position information), 5 neurons in the hidden layer and 1 neuron in the output layer determining the estimated optimum speed. The ANN is trained by means of a modified back-propagation algorithm, based on Levenberg-Marquadt method [8], which allows reducing the training time and improves the convergence as compared with the classical backpropagation training algorithm. 
The output of this module is processed to obtain a smoother reference speed signal in order to decouple the hydraulic system dynamics from the rest of the electromechanical model and to avoid unnecessary speed adjustments during hydraulic transients.

The transfer function of the low-pass filter used to smooth the reference speed signal is given by:

$$
\frac{\omega_{\text {smooth }}}{\omega_{\text {ANNOptimized }}}=\frac{1}{20 s+1}
$$

The smoothing block is shown in Fig. 4.

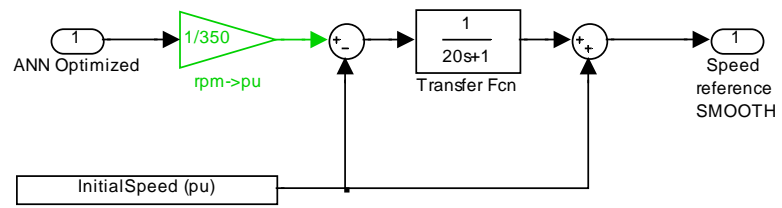

Fig. 4. Smoothing block

\section{Induction generator model}

The mathematical model of the induction machine is based on reference [10]. This model is described in space vector formulation in $\mathrm{dq}$ frame (using per unit description). The used dynamic equations are:

Electrical system equations

$$
\begin{aligned}
& \vec{V}_{s}=R_{s} \vec{i}_{s}+\frac{1}{\omega_{0}} \frac{d \vec{\lambda}_{s}}{d t}+\omega_{k} M \vec{\lambda}_{s} \\
& \vec{V}_{r}=R_{r} \vec{i}_{r}+\frac{1}{\omega_{0}} \frac{d \vec{\lambda}_{r}}{d t}+\left(\omega_{k}-\omega_{m}\right) M \vec{\lambda}_{r}
\end{aligned}
$$

Flux linkage-current relations:

$$
\begin{aligned}
& \vec{\lambda}_{s}=L_{s} \vec{i}_{s}+L_{m} \vec{i}_{r} \\
& \vec{\lambda}_{r}=L_{r} \vec{i}_{r}+L_{m} \vec{i}_{s}
\end{aligned}
$$

Mechanical system equations:

$$
\begin{aligned}
& T_{\text {elec }}=\lambda_{d s} i_{q s}-\lambda_{q s} i_{d s} \\
& T_{\text {turbine }}-T_{\text {elec }}=J \frac{d \omega_{\text {mec }}}{d t}+B_{m} \omega_{\text {mec }}
\end{aligned}
$$

The frequency applied to stator varies until the generator speed matches the smoothed optimum speed reference. The voltage magnitude is adjusted accordingly to maintain constant flux conditions.



Fig. 5. Dynamic model of adjustable speed hydro plant

\section{Complete model}

The hydraulic system, including the ANN Optimum speed module and the smoothing block is connected to the generator subsystem, as shown in Fig. 5. A PID speed controller has been added to provide the changes in the supply frequency needed to adapt turbine speed to its optimum value.

\section{Simulation Results}

A detailed simulation has been carried out in order to evaluate the dynamic response to changes in external operational conditions. Main effects analysed during this simulation are: i. Mismatch between initial conditions and optimum reference conditions

ii. Changes in fore bay elevation reference

iii. Changes in external input flow

Above-mentioned effects may represent real situations such as unit start-up, transition from full-load operation to part-load operation, or adaptation to changes in hydrological conditions of the catchment area.

Smooth changes are applied to both the external input flow and the fore bay elevation reference, using a sigmoid function:

$$
\operatorname{sigmoid}(x, a, b)=\frac{1}{1+e^{((-x+a) \cdot b)}}
$$


These changes have been applied sequentially throughout the simulation. Hereafter, model responses to abovementioned changes are described in detail.

Initially, the turbine is running at $320 \mathrm{rpm}$. Fore bay elevation reference, gate position and external input flow are respectively maintained at $65 \mathrm{~m}, 15^{\circ}$ and $12.05 \mathrm{~m}^{3} / \mathrm{s}$, during first seconds of simulation.

With these hydraulic conditions, the reference speed given by the ANN optimum speed module is $269.7 \mathrm{rpm}$, which is significantly lower than the initial turbine speed. The turbine speed matches the reference speed in less than 3 seconds, as it can be observed in Fig. 6 .

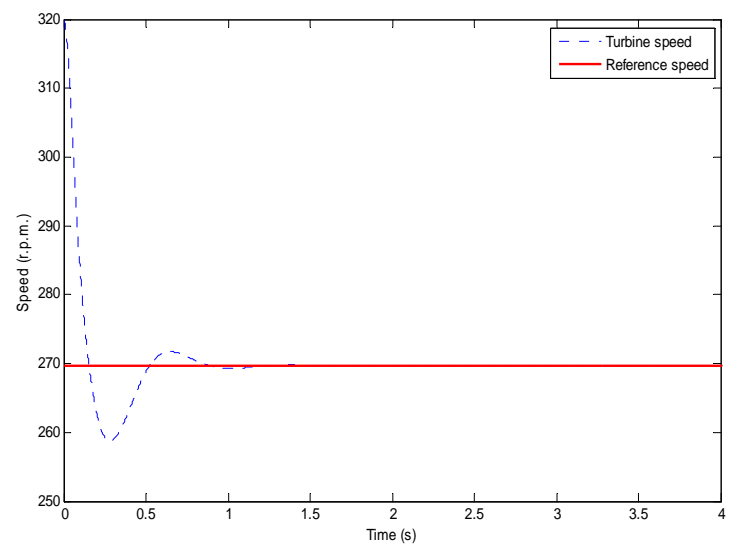

Fig. 6. Turbine speed versus optimum reference speed during first seconds of simulation

At 20 seconds, the fore bay elevation reference initiates a smooth transition towards a final value of $62 \mathrm{~m}$; this process takes about 30 seconds. This transition makes the fore bay elevation undergo some oscillations until it finally matches the modified reference value.

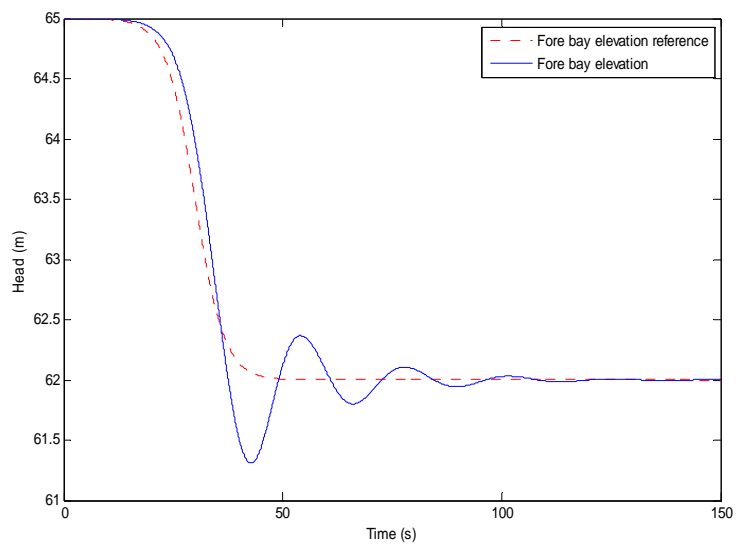

Fig. 7a. Fore bay elevation reference versus fore bay elevation during first 150 seconds.

After the fore bay elevation stabilizes, a smooth change is applied to the external input flow. At 150 seconds, it starts decreasing until a final value of $9.64 \mathrm{~m}^{3} / \mathrm{s}$ is reached at 180 seconds; this value corresponds to a $20 \%$ decrease with respect to the initial input flow. This change causes some oscillations in the fore bay elevation in a similar way to those prompted by the change in fore bay elevation reference.



Fig. 7b. Fore bay elevation reference versus fore bay elevation during last 200 seconds.

Fig. 8 shows the relationships among the input hydraulic variables -external input flow and fore bay elevation reference- and the gate position, throughout the simulation. It can be seen how guide vanes respond to the above-mentioned changes in order to keep the fore bay elevation in its reference value.
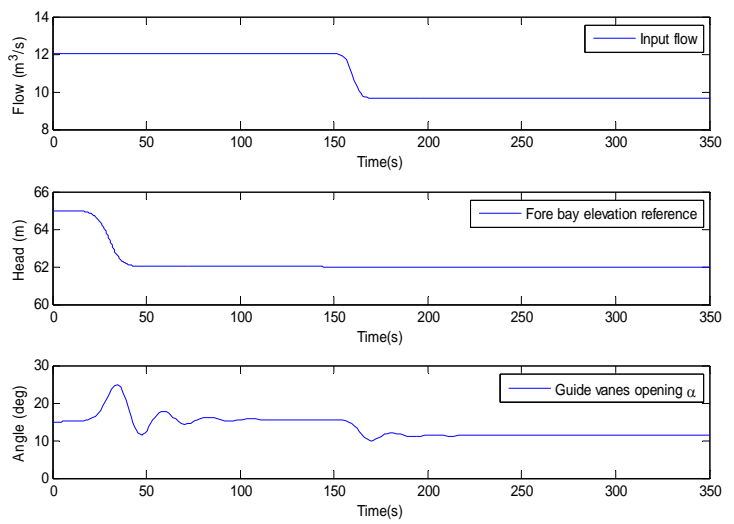

Fig. 8. Guide vanes opening response versus external input flow and fore bay elevation reference

The turbine operating point follows a trajectory over the plane unit speed-unit flow, depicted as a phase plane in Fig.s 9a-9b, where the turbine hill curves are superimposed. The first one represents the first 150 seconds of simulation. The "near-horizontal" segment corresponds to the period when the initial mismatch between the turbine speed and the optimum reference speed is offset, whereas the curved part corresponds to adaptation to new fore bay elevation reference.

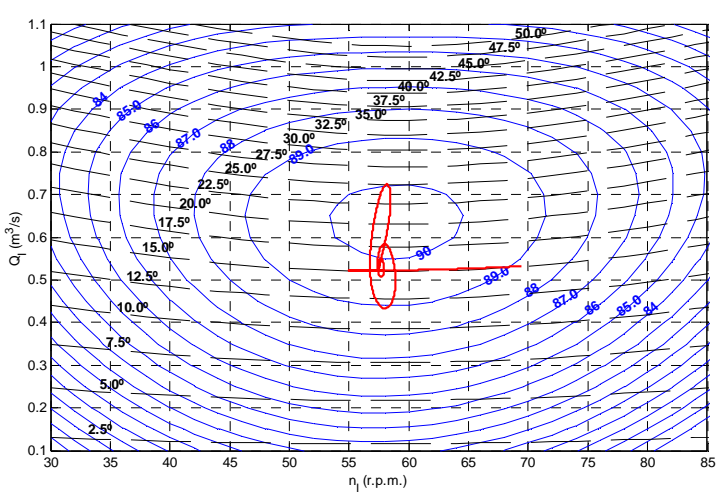

Fig. 9a. Trajectory of the turbine operating point during first 150 seconds 
Fig. 9b represents the last 200 seconds of simulation. The trajectory followed by the operating point due to the change in external input flow is shown in this figure.

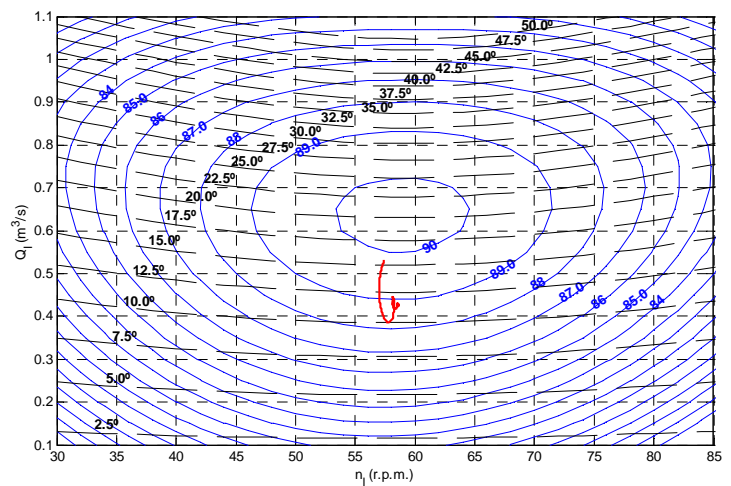

Fig. 9b. Trajectory of the turbine operating point during last 200 seconds

Smoothing block effects can be observed in Fig. 10. As it is shown there, the output of the low-pass filter (see Fig. 4), called "Speed reference SMOOTH", attempts to avoid abrupt speed adjustments during hydraulic transients, by smoothing the optimum reference speed given by the ANN optimum speed module.

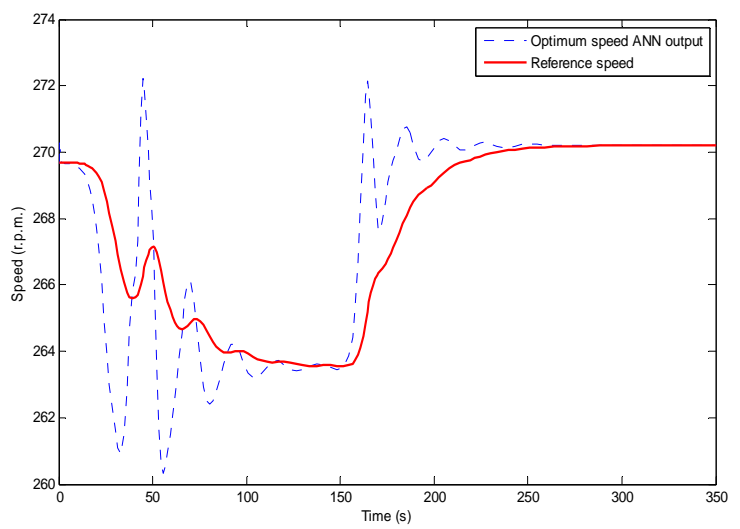

Fig. 10. Smoothing block effects

Finally, the response of electrical variables such as stator current and voltage magnitudes, and normalized active and reactive power, are respectively represented in Figs. 11 and 12.


Fig. 11. Current and voltage magnitudes
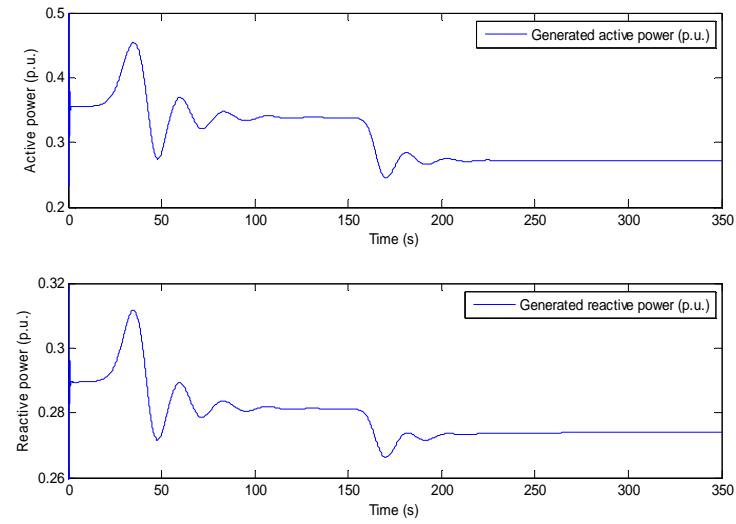

Fig. 12. Generated active and reactive power

\section{Conclusions}

A complete model of speed control of a run-of-river variable speed hydro plant is presented in this paper.

The dynamics of the main subsystems involved are represented in the model. The hydraulic subsystem includes fore bay and penstock dynamics, as well as a detailed model of turbine hill curves. In the generation subsystem, electromagnetic and inertial effects are considered, but the converter is supposed to be ideal.

This model allows verifying the adequacy of the controller used to adapt the unit speed to its optimum value.

An optimum speed module (OMS) based on artificial neural network has been developed. This module generates an optimum speed value from the gate position and the turbine flow.

The reference optimum speed is smoothed in order to decouple the hydraulic dynamics from the rest of the system. The aim of this smoothing is to avoid speed adjustment during hydraulic transients that could add unwanted oscillations.

Some significant events have been simulated to evaluate the dynamic response to changes in operational conditions, defined by fore bay elevation reference and external input flow.

The simulation shows how the control system adjusts the turbine speed to its most efficient value for each particular hydraulic operating condition. Any mismatch between smoothed reference speed and generator speed is cleared in few seconds Fore bay elevation is kept constant to its reference value though important perturbations in external input flow are taking place. 


\section{APPENDIX (NOMENCLATURE)}

The notation used throughout this paper is stated as follows:

\section{Hydraulic parameters}



\section{Electrical parameters}

$\begin{array}{ll}\vec{V} & \text { Voltage space vector [p.u.] } \\ \vec{i} & \quad \text { Current space vector [p.u.] } \\ \vec{\lambda} & \quad \text { Flux linkage space vector [p.u.] } \\ M & \quad \pi / 2 \text { rotational matrix }\left[\begin{array}{cc}0 & -1 \\ 1 & 0\end{array}\right] \\ R & \text { Resistance [p.u.] } \\ L & \text { Inductance [p.u.] } \\ \omega_{0} & \text { Base frequency [p.u.] } \\ \omega_{k} & \text { dq frame reference speed [p.u.] } \\ \omega_{m} & \text { Rotor speed [p.u.] } \\ T_{\text {elec }} & \text { Electromagnetic torque [p.u.] } \\ J & \text { Rotor moment of inertia [p.u.] } \\ B_{m} & \text { Damping [p.u.] }\end{array}$

Simulation parameters

$a, b \quad$ Adjustable parameters used to fix both the starting time and the slope of changes in model inputs

\section{References}

[1] Plan de Energías Renovables en España (20052010). IDAE (Instituto para la Diversificación y el Ahorro de la Energía).

[2] Status report on variable speed operation in Small Hydropower, published on Internet: http://europa.eu.int/comm/energy/res/sectors/small hydro dissemination en.htm

[3] International Small-Hydro atlas, www.smallhydro.com

[4] Merino, J.M., López, A. “ABB Varspeed generator boosts efficiency and operating flexibility of hydropower plant”, ABB Review 3/96. pp. 33-38.

[5] Campos Barros, J. G., Saidel, M. A., Ingram, L., Westphalen, M. "Adjustable speed operation of hydroelectric turbine generators", Electra, n ${ }^{\circ}$ 167, pp. 17-36, August, 1996.
[6] Wilhelmi, J.R., Fraile-Ardanuy, J., Fraile-Mora, J., Íñigo, L. "Adjustable speed hydro generation” Proc. of the International Conference on Renewable Energy and Power Quality, ICREPQ'2003, paper $\mathrm{n}^{\circ}$ 360, 2003.

[7] Fraile-Ardanuy, J., Wilhelmi, J.R, Fraile-Mora, Íñigo, L. "A neural controller for an adjustable speed hydro generator" 8 Congresso Luso-Espanhol de Engenharia Electrotécnica. Vol. 3, pp. 62736278, Vilamoura (Portugal), 3-5 de Julio de 2003.

[8] Fraile-Ardanuy, J., Wilhelmi, J.R, Fraile-Mora, J. I. Pérez e I. Sarasúa, "Dynamic Model and Control of a Variable Speed Asynchronous-Machine Hydro Plants" I Seminario de Aplicaciones Industriales de Control Avanzado, SAICA 2005, Vol. 1, pp. 157168, Madrid (España) 19-20 Octubre de 2005.

[9] Fraile-Ardanuy, J., Wilhelmi, J.R, Fraile-Mora, J. I. Pérez e I. Sarasúa, "A Dynamic Model of Adjustable Speed Hydro Plants”, 9 Congreso Hispano Luso de Ingeniería Eléctrica, Marbella (España), 30 Junio a 2 de Julio de 2005.

[10] Mohan, N. "Advanced Electric Drives. Analysis, Control and Modeling using Simulink ${ }^{\circledR}$ ”, MNPERE, 2001. 